\title{
Evropeizacija in lokalizacija komemoracij ob stoletnici prve svetovne vojne
}

Tatiana Bajuk Senčar

Stoletnico prve svetovne vojne sestavlja niz dogodkov, ki po mnenju mnogih analitikov pomenijo doslej najbolj intenzivno in izjemno predstavitev kolektivnega spomina, povezanega $\mathrm{z}$ omenjenim konfliktom. Besedilo, v katerem predstavljam raziskavo o stoletnih komemorativnih praksah prve svetovne vojne, ${ }^{\mathbf{1}}$ ima za cilj raziskovanje posebnosti stoletnice kot dogodka družbenega spomina, ki poteka na

1 Prispevek temelji na raziskavi, izvedeni v sklopu projekta, z naslovom $\gg$ Dediščina prve svetovne vojne: Reprezentacije in reinterpretacije (2016-2018)«, ki ga je financirala Javna agencija za raziskovalno dejavnost Republike Slovenije (št. J67173). O projektu gl. tudi Jezernik in Fikfak 2018. Prispevek tudi delno temelji na programu Etnološke in folkloristične raziskave kulturnih prostorov in praks (P60088). 
številnih, med seboj povezanih ravneh, in združuje države s skoraj vseh celin. Raziskava temelji na domnevi, da se vojne komemoracije spreminjajo skozi leta ter se med seboj razlikujejo glede na različne politične, kulturne in družbene okoliščine. Poleg tega obstajajo številni posebni dejavniki in procesi, ki sooblikujejo sedanjo dobo in stoletne programe, ki se izvajajo po vsem svetu.

Eden od najpomembnejših procesov, ki oblikujejo sodobne spomine, je memory boom, izraz, ki ponazarja na novo oživljeno oziroma obnovljeno zanimanje za preteklost v zadnjih desetletjih zlasti s strani držav in družb -, ki preteklost uporabljajo zato, da ji podeljujejo sedanje pomene (Beaumont 2015; Bell 2006; Berliner 2005; MacDonald 2013). Drugi, pomemben proces je postopen razvoj vojaškega turizma, določenega sektorja turistične industrije, ki se je razvil od romanja, vojaških spomenikov in pokopališč do povečanega (in bolj splošnega) interesa za obisk krajev oboroženih spopadov (Bajuk Senčar 2018; Jansen-Verbeke in George 2013; Kravanja 2018; Salazar 2009; Winter 2009). Nedavni in hkrati prav tako pomemben proces je razvoj digitalne tehnologije, ki omogoča zbiranje, shranjevanje, dostopanje in razširjanje različnih spominov in zgodovin - od uradnih, nacionalnih do osebnih ali družinskih -, kar omogoča vključitev vrste izkušenj in družbenih akterjev v komemorativne projekte in dogodke (Bajuk Senčar 2019). Zelo pomemben dejavnik, ki ga velja v tem kontekstu posebej omeniti, pa je dejstvo, da je stoletnica prva večja obletnica vojne, ki se dogaja ob odsotnosti prič, to je preživelih vojakov vojne, ki so pomenili živi stik z zgodovino in so zaradi tega vedno imeli tradicionalno pomembno vlogo na spominskih slovesnostih.

Glede na povedano je mogoče trditi, da stoletnica ne pomeni radikalne spremembe $\mathrm{v}$ primerjavi $\mathrm{z}$ dogajanji na prejšnjih komemoracijah. Namesto tega so se njihove priprave in izvrševanje opravljali v okviru določenih široko zastavljenih okoliščin, seveda poleg zgodovinskih, kulturnih in političnih posebnosti. Vse te informacije vplivajo na strukturo in pomen stoletnih programov: komu so namenjeni in kako so oblikovani; kdo so udeleženci in katere vloge igrajo. Ne nazadnje tudi, kakšne so te vrste sprememb, ki jih lahko opazimo, še posebej na evropski ravni?

Da bi bolje razumeli posebnosti komemoracij ob stoletnici, se $\mathrm{v}$ razpravi najprej osredotočam na razvoj vloge države in nacionalnega kot dosedanji »samoumevni « referenčni okvir za spominske dogodke in prakse v sedanjosti. Če se ozremo na leta vojnih komemoracij, je očitno, da so uradne slovesnosti potekale predvsem na nacionalni ravni. Vloga, ki jo ima država, je povezana z dolžnostjo, ki ji 
velikokrat pripisujemo spominjanje, zaradi česar pogosto prevzame vodilno vlogo pri pripravi in izvajanju komemorativnih slovesnosti in praks (Wouters 2016). Nacionalna prizorišča komemoracij so najpogosteje ob ključnih spomenikih, kjer so nacionalni voditelji kot predstavniki države navadno v središču pozornosti. To seveda ne pomeni pomanjkanja spominskih prireditev na drugih ravneh, ampak to, da so do zdaj bili nacionalni dogodki in projekti deležni reprezentativnega statusa - v sklopu vloge nacionalne države kot akterja v oboroženih spopadih.

Ob tem se zastavlja vprašanje, ali je država - kljub svoji zgodovinski vlogi - ostala glavni dejavnik in akter komemorativnih praks $\mathrm{v}$ primeru stote obletnice prve svetovne vojne ali pa postajajo drugi akterji ali referenčni okvirji pomembnejši in primernejši. Nekateri analitiki so se spraševali, ali bi stoletnica lahko služila kot priložnost za razvoj »nove sinteze spominov na vojno «, sinteze, ki bi delovala kot skupni referenčni okvir, s katerim bi bilo mogoče preseči razlike med nacionalnimi spomini (npr. Beaumont 2015: 535). Ideja, da bi stoletnica lahko postala dogodek za razvoj enotnega, skupnega okvira za vojne spomine se večini zdi nerealistična. Vseeno pa se postavlja vprašanje, ali je stoletnica postala navdih za bolj vključujoče razumevanje vojne, zlasti na evropski ravni.

Ob tem pa sodobni trendi kažejo na vse večji pomen lokalnih akterjev pri gradnji, ohranjanju in spominjanju izkušenj iz vojne. Zgodovinar Jay Winter trdi, da je ena od posebnosti stoletnice rastoči pomen lokalnih komemoracij in okvirov spominskih slovesnosti, kar po njegovem mnenju kaže na downward shift oziroma »premik navzdol « v komemorativnih praksah:

\footnotetext{
$\mathrm{V}$ tisočih projektov, predstavljenih francoski predsedniški komisiji na stoletnico (na kateri sedim), velika večina prosi za priznanje in finančno podporo za razstave, koncerte ali druge prireditve, ki so bile organizirane na lokalni ravni ... Čim manjše, tem boljše, se zdi, da je bila skupna smernica, ki omogoča, da se široko obzorje velike vojne zmanjša na naše mesto, četrt ali okolico. (Winter 2017: 241)
}

Ali je ta »premik navzdol«, ki ga je Winter opazil v primeru Francije, vsesplošen trend in ali je stoletnica nemara s seboj prinesla potrditev drugih spominskih praks, ki niso nacionalne? Kot odgovor na ta vprašanja sledi razprava o vlogi nacionalnih držav na stoletnih obeležjih v Evropi in naravi spominskih programov v različnih državah v Evropi, vključno s Slovenijo, podrobneje tudi o slovenskem primeru s poudarkom na analizi stoletnice v Bohinju. 
Medtem ko lahko ob stoletnici zaznavamo velik porast spominskih slovesnosti po vsem svetu, analiza obstoječih študij posameznih nacionalnih programov - kot tudi nekaj primerjalnih analiz - kaže na raznolikost med državami glede pristopa, vsebine in širšega pomena. Tudi boj na isti strani v istih bitkah ni zagotovilo, da se države spominjajo svojih vojnih izkušenj na podobne načine. Pogosto določene okoliščine na nacionalni ali podnacionalni ravni delujejo kot odločilni dejavniki pri izoblikovanju komemorativnih praks. Čeprav temeljita razprava o teh dejavnikih precej presega meje tega eseja, bom na kratko predstavila nekatere od njih.

Eden od pomembnih dejavnikov, ki vpliva na vojne komemoracije, še posebej, če primerjamo države v zahodni Evropi, je lokacija: ali so se vojaki določene države borili »na fronti《 ali pa na frontnih črtah daleč od doma. Določeni analitiki trdijo, da je mogoče zasledovati korelacijo med intenzivnostjo spominskih praks in lokacijo frontnih črt, pri čemer sta Francija in Belgija - ali natančneje regija Flandrije v Belgiji - v zvezi s tem še posebej dejavni v primeru zahodne fronte. Ben Wellings, ki je primerjal spominske programe različnih držav zahodne Evrope, je v tem kontekstu izpostavil dejavnosti Francije:

Francoski državi je pripadla dolžnost organizacije večine spominskih dogodkov za obdobje 2014-2018. Francoska vodilna vloga $\mathrm{v}$ tem pogledu ni presenetljiva, saj je večina spopadov na zahodni fronti potekala prav na francoskih tleh. Zato ni presenetljivo, da je francoski diplomatski zbor eden največjih na svetu in sposoben izpolniti zahteve, ki jih ustvarja tak globalni spominski program. (Wellings 2016: 105)

Medtem ko je Wellings v svoji razpravi izpostavil Francijo zaradi obsega in intenzivnosti programa, je Nico Wouters v svoji analizi stoletnice v Belgiji trdil, da je lokacija na frontnih linijah vplivala na pristop in poudarek pri komemoracijah stoletnice. Flandrija, regija, kjer je potekala večina bojev v Belgiji, je bila še posebej aktivna pri načrtovanju lastnega programa, ki je poudarjal izkušnje na fronti in bitke $s$ pomočjo obstoječih spomenikov in muzejev kot temeljev za spominske slovesnosti in dogodke. Ti so bili namenjeni tudi podpori turizma ob frontni črti, kot pojasnjuje Nico Wouters:

Flamski akcijski načrt iz leta 2011 je pokazal velike ambicije, predvsem na področju (mednarodnega in nacionalnega) turizma 
ter mednarodnih odnosov. Velike javne naložbe so bile izvedene $\mathrm{v} \gg$ strateških projektih « (npr. na Flandrijskem polju in v muzeju Passchendaele) kot tudi v posameznih lokalnih projektih. Glavna pripoved o osrednji flamski politiki je bila preprosta: označevanje Flandrije kot globalnega središča za mednarodni mir in sprave.

(Wouters 2016: 78)

V svoji analizi je Wouters flamski program postavil v širši, nacionalni kontekst, pri čemer je izpostavil pomen federalizirane državne strukture Belgije za komemorativno načrtovanje. Belgija je sestavljena iz avtonomnih in konkurenčnih regij, Wouters pa pri tem opozarja, da sta tako struktura kot zgodovina med regijami prispevali $\mathrm{k}$ temu, da je prav vsaka regija razvila lasten komemoracijski program. Vse to je ob upoštevanju pogosto spornih odnosov med regijami pripeljalo do določene stopnje »spominske konkurence « in debat zaradi pomanjkanja bolj splošne, vključujoče pripovedi (Wouters 2016).

Ob tem velja pripomniti, da se vprašanje o federalizirani ali centralizirani državni strukturi ni nujno pojavilo na enak način v vsaki državi. Annika Mombauer je v svoji analizi nemške stoletnice preučila zadržano vlogo nemške zvezne vlade. Navaja, da neučinkovitost nemške zvezne vlade ni bila posledica strukturne dinamike v državi, temveč njene zaskrbljenosti z razpravami o zgodovinski odgovornosti nemške vlade za dogodke, ki so privedli do izbruha prve svetovne vojne - razprave, ki so tudi zajele pozornost nemških akademikov, novinarjev in splošne javnosti. Vpletenost zvezne vlade $\mathrm{v}$ te omenjene razprave je privedlo do njene neaktivnosti ali celo do njene nepripravljenosti za načrtovanje nacionalnih komemoracij. Iz tega je sledilo, da so večino stoletnih dogodkov organizirale (razmeroma močne) regionalne vlade in institucije po vsej državi (Mombauer 2017; glej tudi Bayer 2015). V tem primeru je zadržanost državnih voditeljev ustvarila prostor delovanja, ki so ga prevzeli akterji in organizacije na nižjih ravneh. Tovrstni pristop se precej razlikuje od močno centraliziranega programiranja, značilnega za stoletno organizacijo v Franciji, kjer je država usklajevala (in celo sofinancirala) dejavnosti na vseh ravneh (Winter 2017).

Primer Nemčije izpostavlja dodatno vprašanje o tem, kako se $\mathrm{v}$ različnih državah spominjajo določenega konflikta in kako se ti spomini umeščajo v kontekst širše zgodovine posamezne države. Wellings trdi, na primer, da je treba razumeti vplive druge svetovne vojne in posledično pomembno vlogo, ki jo imata zgodovinsko razmišljanje in spopadanje s preteklostjo (Vergangenheitsbewältigung) na sodobno nemško javno življenje. Le tako bi razumeli, kako nemška zvezna država pristopa $\mathrm{k}$ spominjanju prve svetovne vojne. 
V svoji analizi irskega stoletnega programa Catriona Pennell dokazuje, da je treba pomen in cilj irske stoletnice gledati v širšem časovnem okviru, v katerem je potekala stoletnica. Stota obletnica na Irskem je bila le ena od prireditev $v$ širšem nizu komemoracij, uradno opredeljenih kot desetletje stoletnic, ki so se nanašale na vrsto revolucionarnih dogodkov in konfliktov v letih od 1913 do 1923; ne nazadnje so prav ti pripeljali do ustanovitve sodobne Irske (Pennell 2017: 256). Medtem ko prva svetovna vojna za Irsko zagotovo ni bila nepomemben dogodek, je njena stoletnica na nacionalni ravni upodobljena kot element širše - in vključujoče - irske nacionalne pripovedi in identitete, ki sta delovali kot središče celotnega spominskega desetletja. Program stoletnice vojne je bil namenjen preseganju razlik med komemoracijskimi praksami nacionalnih frakcij ter je služil kot forum za spravo na ravni spomina na vojne in spominske prakse (Pennell 2017: 265).

Ob primerjavi omenjenih primerov je opazno, da igrajo državni organi zelo različne vloge: lahko so organ za načrtovanje, razsodnik med regijami, udeleženec v zgodovinskih razpravah ali ustvarjalec nacionalnih pripovedi. Kljub tej raznolikosti lahko opazimo znatno povečanje aktivnosti na regionalni in lokalni ravni. Kaj to pomeni za tradicionalno spominsko vlogo države in oblikovanje vojnega spomina na nacijo, $v$ imenu katere so potekali konflikti in so bila izgubljena življenja?

\section{DRŽAVE KOT MEDNARODNI KOMEMORACIJSKI AKTERJI}

Da bi odgovorili na to vprašanje, zlasti v zvezi z vlogo države $\mathrm{v}$ produkciji bolj vključujočih, to je evropskih referenčnih okvirjev, je treba obravnavati vlogo države na mednarodni ravni, v skupnosti narodov. Beaumont trdi, da je bilo, zgodovinsko gledano, transnacionalno sodelovanje pri spominjanju vojne do neke mere neizogibno, saj je že fizična zgradba spomenikov ob nekdanji zahodni fronti zahtevala sodelovanje med zavezniki takoj po vojni (Beaumont 2015: 534). V naslednjih letih se je sodelovanje med državami razvilo $\mathrm{v} \gg$ spominsko diplomacijo «, ki jo izvajajo izbrani nacionalni voditelji v »skrbno koreografiranih javnih slovesnostih [...] ob obletnicah zgodovinskih dogodkov na izbranih mestih spomina, dolgoletnih ali nedavnih izumih, po navadi ob srečanju mednarodnih vrhov ali medvladnih forumov « (Graves 2014: 170). Te slovesnosti delujejo kot prizorišče in priložnost za spodbujanje bolj pozitivnih dvo- in večstranskih odnosov ter širjenje posebnih diskurzov, povezanih z vojno. 
Medtem ko so nacionalne komemoracije predvsem namenjene državljanom ter delujejo kot forum za spominjanje in spoštovanje padlih vojakov določene države, je primarno sporočilo transnacionalnih spominov sprava in mir med državami (poleg čaščenja vojakov). Francoski in nemški voditelji so $\mathrm{v}$ zadnjih desetletjih igrali simbolno vlogo pri tem. Ena najbolj znanih je bila slovesnost v Verdunu leta 1984, na kateri je francoski predsednik François Mitterrand povabil nemškega kanclerja Helmuta Kohla na slovesnost spomina in sprave. Podoba obeh moških, ki sta se držala za roko pred kostnico Douaumont v Verdunu, je obkrožila svet; ta slovesnost je tudi napovedala novo dobo francosko-nemških odnosov.

Kostnica Douaumont je znova postala prizorišče podobne slovesnosti ob praznovanju stoletnice bitke pri Verdunu leta $2016 \mathrm{~s}$ francoskim predsednikom Françoisem Hollandom in nemško kanclerko Angelo Merkel. Oba državna voditelja sta obeležila zgodovinsko obletnico s skupno slovesnostjo, med katero sta položila vence $\mathrm{v}$ čast vsem padlim vojakom. Ob tem sta podala širši poziv za evropsko enotnost in mir. Predsednik Hollande je pozval ljudi, naj »ljubijo svojo državo, vendar pa moramo zaščititi naš skupni dom, Evropo, brez katere bi bili izpostavljeni nevihtam zgodovine «. Kanclerka Merkel pa je izjavila: $\gg$ Če razmišljamo samo v nacionalnem smislu, ne moremo napredovati. To velja za reševanje evropske dolžniške krize kakor tudi za sprejem beguncev (Chazan 2016).«

Transnacionalne slovesnosti stoletnice so pogosto potekale $\mathrm{v}$ nekem evropskem (ali EU) referenčnem okviru, kljub temu da institucije EU niso oblikovale lastnih programov, ${ }^{2}$ kar je razumljivo, saj je EU nastala šele po drugi svetovni vojni. Kljub temu pa se državni voditelji v okviru vojnih komemoracij pogosto sklicujejo na določena pojmovanja Evrope oziroma EU, in poudarjajo sodobni, domnevno povezovalni koncept Evrope. Prej navedeni izjavi obeh voditeljev kažeta Evropo kot skupni dom narodov, ki živijo v sožitju, in Evropo oziroma EU, ki je oziroma mora biti forum za reševanje izzivov, ki presegajo posamezne države. Stoletno praznovanje v Verdunu, ki je temeljilo na tradiciji spominjanja sprave v Evropi, je postalo mesto sodobnih evropskih okvirov, znotraj katerih niso obravnavali le zgodovinskih dogodkov iz preteklosti, temveč tudi trenutne izzive, $s$ katerimi se spopadajo številne evropske države. obeležili 100-letnico začetka vojne (BBC News 2014), in posebna razprava v Evropskem parlamentu, ki je aprila 2014 obeležila stoletnico (Evropski parlament 2014). 
Kakšni so bili programi stoletnic v Sloveniji? Če začnemo s pripravami, je bil slovenski program podoben tistemu v Franciji, saj je država delovala kot osrednje organizacijsko telo. Slovenska država je leta 2012 ustanovila organizacijski odbor v pristojnosti Ministrstva za obrambo: Nacionalni odbor za obeležitev 100-letnic 1. svetovne vojne. Ta odbor, sestavljen iz predstavnikov države, nacionalnih arhivov, knjižnic, raziskovalnih ustanov in turistične industrije ter lokalnih občinskih voditeljev, je bil zadolžen za usklajevanje aktivnosti na nacionalni, regionalni in lokalni ravni ter komemorativnih slovesnostih v tujini. Prvi predsednik odbora, minister za obrambo Roman Jaklič, je trdil, da je glavni namen odbora, da prispeva $k$ utrditvi kolektivnega zavedanja na Slovenskem o pomenu prve svetovne vojne za življenje prebivalcev in celotno skupnost ne le politično, temveč predvsem $\mathrm{v}$ smislu raznovrstnih izkušenj, ki jih je prinesla vojna (Ministrstvo za obrambo 2014). ${ }^{3}$

V sporočilu za javnost, objavljenem na spletni strani programa slovenske stoletnice, je imel odbor štiri glavne naloge: olajšati usklajevanje aktivnosti kulturnih, akademskih in pedagoških institucij in združenj na regionalni in lokalni ravni; organizirati in pomagati pri izvedbi dogodkov, še posebej osrednjih dogodkov programa; vzdrževati stike s tujimi veleposlaništvi v Sloveniji in slovenskimi veleposlaništvi v tujini glede stoletnih dogodkov; ustvariti skupno podobo za dogodke in aktivnosti stoletnega programa. ${ }^{4}$ Dodatno pomembno delo odbora se je nanašalo na promocijo in diseminacijo stoletnih dogodkov, ne le zato, da bi okrepili kolektivni spomin Slovencev, temveč tudi za promocijo slovenskih izkušenj zunaj Slovenije, s čimer bi zagotovili priložnosti za Slovenijo v turizmu (Ministrstvo za obrambo 2014). Med diseminacijskimi nalogami je bila tudi izdelava spletne strani: www.100letprve.si. Ta spletna stran je služila kot platforma za delo odbora in je vključevala vse, kar je bilo povezano s slovensko stoletnico, vključno z uradnim razporedom vseh stoletnih dogodkov, ki so se izvajali v Sloveniji, kot tudi dogodkov, ki so bili izvedeni v tujini s pomočjo slovenske države. $\mathrm{Na}$ spletni strani so tudi povezave do stoletnih dogodkov in projektov, ki se izvajajo po vsej Evropi in zunaj nje. utrjevanje kolektivnega zavedanja o posledicah 1. svetovne vojne. Novica Ministrstva za obrambo. 8.4. 2014. URL: http://www.mo.gov.si/si/medijsko_sredisce/novica/7085/ Nacionalni odbor za obeležitev 100-letnic 1. svetovne vojne (2014-2018) se predstavi. URL: ttp://www.100letprve.si/noga/nacionalni_odbor_za_obelezevanje_100letnic_1_ svetovne_vojne/index.html 
Uradni urnik stoletnih dogodkov omogoča pomemben vpogled $\mathrm{v}$ obstoječo paleto spominskih akterjev, njihovih dejavnosti in vrste partnerstev, ki so se oblikovali za organizacijo stoletnih dogodkov. Izbrana skupina nacionalnih in regionalnih institucij je bila med najbolj aktivnimi akterji v stoletju. To skupino sestavljata nacionalni muzej (Muzej novejše zgodovine Slovenije) in skupina regionalnih muzejev (Kobariški muzej, Tolminski muzej, Goriški muzej), ki se nahajajo v bližini soške fronte. Najbolj dejavna institucija stoletnega programa je bila Fundacija Poti miru v Posočju, ki je delovala ne le na lokalni, temveč tudi na regionalni in mednarodni ravni, največkrat $\mathrm{v}$ povezavi $\mathrm{z}$ institucijami $v$ Italiji.

Pri analizi približno 400 dogodkov programa je bilo razvidno, da so veliko večino prireditev organizirale lokalne organizacije: občine, kulturnozgodovinska in pohodniška združenja, turistične organizacije, lokalne knjižnice in galerije, osnovne in srednje šole. Številni lokalni dogodki so potekali v bližini in zaledju soške fronte, podobno kot v Franciji in Belgiji, ki sta bili prizorišči frontnih črt. Temu je treba dodati, da so bile na seznamu zastopane tudi lokalne organizacije iz vse Slovenije. Na primer Knjižnica Mirana Jarca v Novem mestu je 10. aprila 2014 gostila referat zgodovinarja Mitje Sadeka z naslovom »Kaj od prve svetovne vojne hranijo novomeške kulturne ustanove «. Drug primer je odprtje razstave, ki sta jo organizirala Pokrajinski muzej Ptuj-Ormož ter Zgodovinski arhiv na Ptuju z naslovom »Živeti z vojno, prva svetovna vojna na ptujsko-ormoškem območju « in je potekala od julija do septembra 2016. Tako sta lokalna dogodka izpostavljala lokalne razsežnosti vojnih izkušenj. ${ }^{\mathbf{5}}$

Slovenska država je tako usklajevala in centralizirala dejavnosti, ki so potekale po vsej državi. To se ni nanašalo le na nadzor glede vsebine ali časovne razporeditve, temveč je delo odbora vsebovalo tudi zagotavljanje nekega logističnega okvira in podporo, tudi v smislu promocije in povezovanja $v$ tujini. Država je ob tem tudi zagotovila široko zasnovan konceptualni okvir, povezan z zbiranjem in krepitvijo kolektivnega spomina o slovenskih izkušnjah vojne, okvir, ki je vključeval tudi evropsko dimenzijo, kot je razvidno iz naslednje izjave slovenskega stoletnega odbora:

Republika Slovenija se je poleti 2012 z ustanovitvijo Nacionalnega odbora za obeleževanje 100-letnic 1. svetovne vojne (2014-2018) dejavno vključila v vseevropsko počastitev stoletnice začetka 1 . svetovne vojne. $\mathrm{V}$ skladu s slovensko izkušnjo te vojne in kolektivnim 
spominom se je odločila za delovanje $\mathrm{v}$ duhu preseganja delitev, ki so leta 1914 Evropo pahnile v vojno, krepitve idej sobivanja in strpnosti ter medkulturnega in medgeneracijskega dialoga. ${ }^{\mathbf{6}}$

Odbor je deloval kot vključevalni projekt na številne načine, njegova glavna vloga je bila vključevanje izkušenj Slovencev v širši evropski spominski projekt konflikta. Na nacionalni ravni si je prizadeval za vključitev različnih vojnih izkušenj Slovencev v širši, čeprav nacionalni, spominski projekt, namenjen krepitvi kolektivnega spomina. Koncept Evrope, povezan z vključujočim, široko zastavljenim spominskim projektom $\mathrm{v}$ tem kontekstu, ne temelji toliko na samih vsebinah; namesto tega je normativni diskurz komemoracije vojne povezan $\mathrm{z}$ vrednotami, kot so sožitje, strpnost ter medkulturni in medgeneracijski dialog.

Vendar analitični poudarek na aktivnosti slovenske države ponuja le delni vpogled v slovensko stoletnico, saj je bila večina organizatorjev aktivnih na regionalni in lokalni ravni. Tako je bila v skladu $\mathrm{z}$ omenjenimi trendi izvedena tudi večina stoletnih dogodkov; bili so regionalne ali lokalne narave. Kaj je to pomenilo za slovensko stoletnico? Winter v svoji analizi francoske stoletnice trdi, da je povečanje števila lokalnih spominskih dogodkov posledica uvedbe praznovanja ob spominu: »Nihče ne bi mogel praznovati vojne, ki je pustila 1.400 .000 francoskih mrtvih vojakov, vendar bi lahko proslavili prispevek ene občine vojni« (Winter 2017: 341).

\section{KOMEMORACIJA STOLETNICE PRVE SVETOVNE VOJNE V BOHINJU}

Glede na raznolikost prireditev in dejavnosti, ki so se izvajale po vsej državi, je mogoče nekatere odgovore na gornje vprašanje ponazoriti $\mathrm{z}$ analizo lokalnih spominskih aktivnosti $\mathrm{v}$ enem kraju, $\mathrm{v}$ Bohinju, ki je bil sestavni del sistema oskrbe zaledja za soško fronto. Zaradi svojega položaja ob železnici in oddaljenosti od italijanskega topništva je leta 1915 Bohinj postal območje za frontnimi črtami za usposabljanje vojakov, tu so skrbeli za bolne in ranjene, pa tudi za prevoz potrebnih zalog na fronto, zlasti na območjih pri Krnu in Tolminu (Budkovič 1999).

6

http://www.100letprve.si/noga/nacionalni_odbor_za_obelezevanje_100letnic_1_ svetovne_vojne/ 
Ko je bil Bohinj vpet v oskrbovalni sistem soškega zaledja, so prebivalci doživljali vojno na več načinov: od mobilizacije v vojsko, sodelovanja pri izgradnji in vzdrževanju sistema oskrbe zaledja, do vzdrževanja kmetije in gospodinjstva $\mathrm{v}$ težkih časih pomanjkanja. Tistim, ki niso bili mobilizirani, je vključevanje Bohinja v sistem zaledja spremenilo vsakodnevno življenje, preoblikovalo je tudi lokalno pokrajino. Oskrbovalni koridor $\mathrm{v}$ obliki dvotirne železnice in gorske poti ter kot sistem žičnic je bil vgrajen v gorsko pokrajino. Ob koridorju so bili skladišča, vojašnice, pa tudi gorski oskrbovalni tabori, kar je pomenilo gradnjo novih stavb in preoblikovanje obstoječih. Tako so hotele in gradove preoblikovali v bolnišnice, kmetijski zadružni centri in občinska središča pa so postali rehabilitacijski centri. ${ }^{7}$

Bohinjski stoletni program je vseboval vrsto prireditev, vključno s komemorativnimi slovesnostmi, spominskimi mašami, predavanji, umetniškimi razstavami, filmskimi projekcijami, predstavitvami knjig, koncerti, muzejskimi razstavami in spominskimi pohodi po krajih, povezanimi s soško fronto. Bohinj je ob stoletnici že imel uveljavljeno zgodovino komemorativnih praks; bila je osnova za stoletni program. Programske dogodke in aktivnosti lahko razvrstimo v vsaj tri kategorije: prvi so uveljavljene letne spominske prakse; drugi obstoječe aktivnosti, ki so bile preoblikovane v dogodke za stoletnico; tretji pa so bili povsem novi dogodki, organizirani za stoletnico.

Primer uveljavljene spominske prakse je letna spominska slovesnost, ki 1. novembra poteka na vojaških pokopališčih za tiste vojake, ki so našli zadnje počivališče v Bohinju. Od leta 1993 naprej ena od bohinjskih turističnih organizacij organizira spominsko slovesnost na glavnem pokopališču v Ukancu in vabi ambasadorje iz vseh držav, katerih vojaki so pokopani tam. Prireditve so se udeležili veleposlaniki iz Madžarske, Avstrije, Italije, Poljske, Ukrajine, Češke, Slovaške, Romunije, Rusije, Hrvaške, Bosne in Hercegovine, Srbije ter Črne gore. Po besedah turističnega uradnika, ki je v preteklih letih organiziral to slovesnost, je namen komemoracije ohraniti spomin na vse tiste, ki so tam pokopani, ne glede na narodnost, in na grozote vojne, »da se zgodovina ne bi nikoli ponovila «. Dogodek, organiziran na lokalni ravni, tj. s strani lokalnih organizacij in občine, je bil oblikovan kot dogodek na čast vsem padlim, in je prinašal univerzalno sporočilo o ohranjanju miru. Leta 2012 je bila govornica na letni spominski slovesnosti madžarska evropska poslanka Edit Herzog, ki je nagovorila tako lokalno skupnost kot širšo, nadnacionalno publiko. Po eni strani zgodovinski zapis bohinjskega zgodovinarja Tomaža Budkoviča (1999). 
se je prebivalcem Bohinja zahvalila za ohranitev zadnjega počivališča vojakov, hkrati pa je pozvala k miru: da ne smemo ponavljati istih napak, ki so jih naši predniki v prejšnjem stoletju storili dvakrat (Lotrič Ogrin 2012).

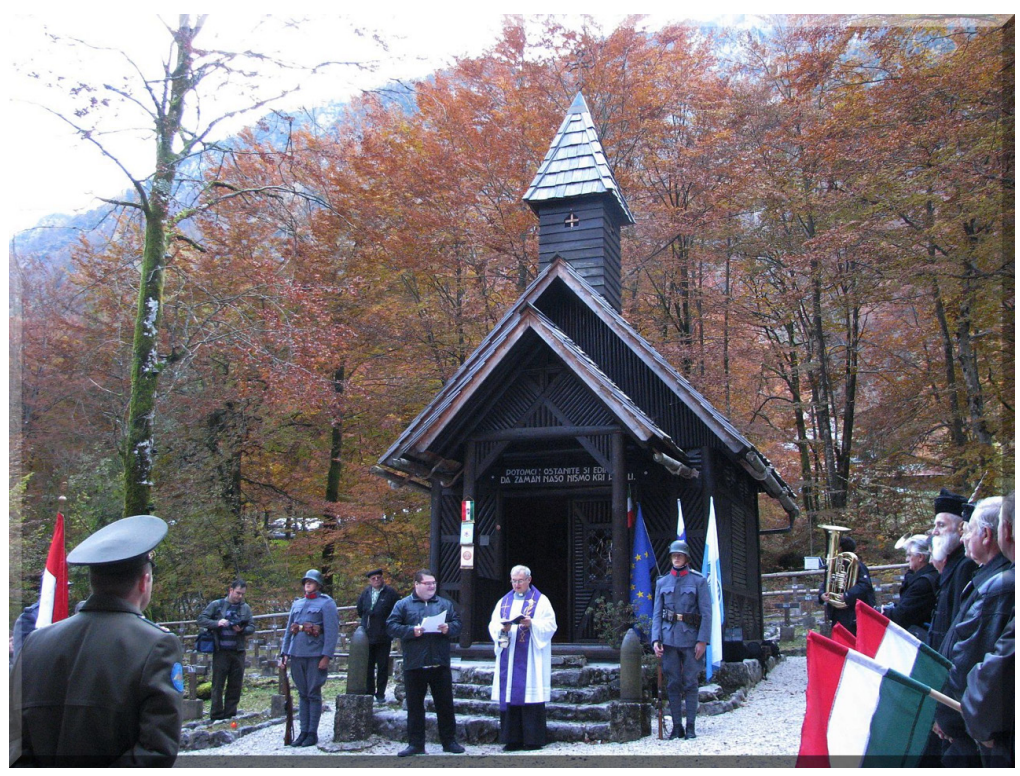

Slika 1: Vojaško pokopališče v Ukancu, prizorišče letne spominske komemoracije padlih vojakov 1. novembra 2011 (foto: Janez Pikon).

Večina prireditev v Bohinju je bila povezana s soško fronto in oskrbovalno potjo, ki je potekala skozi Bohinj. Ta je zelo močno vplivala na tamkajšnje življenje $\mathrm{v}$ času vojne. $\mathrm{V}$ uradni izjavi občine in organizacijskega odbora o dogodkih ob obeležitvi stoletnice soške fronte je bil program predstavljen z naslednjimi besedami:

Ob obletnici začetka bojev na soški fronti smo s sodelovanjem različnih organizacij in društev pripravili nabor dogodkov in prireditev $\mathrm{z}$ namenom, da se spomnimo teh krutih časov in da opozorimo, da se lahko zgodovina vsak čas ponovi, zato so prizadevanja za mir eno glavnih poslanstev moderne družbe. (Košnik 2015)

Iz zgornje izjave je razvidno, da ima vsaka prireditev vsaj dva cilja oziroma namena. Po eni strani gre za spominjanje na lokalno doživljanje vojne, po drugi pa naj služi kot svarilna zgodba z univerzalnim sporočilom o vrednoti miru.

Organizatorji dogodkov poudarjajo bodisi eno bodisi drugo. Tako se pomemben sklop spominskih dogodkov osredotoča na poudarjanje zgodovine prve svetovne vojne v Bohinju kot elementa 
lokalne dediščine, pri čemer imajo lokalni akterji pomembno vlogo pri ohranjanju lokalne zgodovine in kolektivnega spomina v Bohinju med vojno tako za nadaljnje generacije kot tudi za širše občinstvo. Tak primer je predstavitev kompilacije ustnih zgodb o vojni, ki jih je etnologinja Marija Cvetek (2014) prepisala v lokalnem narečju. $\mathrm{Ob}$ predstavitvi knjige so prebrali del zgodb v lokalnem narečju. Prireditev je bila posvečena tako spominu na lokalne vojne kot tudi bohinjski jezikovni zapuščini:

\begin{abstract}
Verz iz te vojaške ljudske pesmi spremlja vsebino knjige - bohinjske pripovedi, ki s svojo pristno narečno govorico oživljajo mnoge spomine na vojni čas in tako žlahtno dopolnjujejo na tisoče zgodovinskih podatkov, ki so nam dostopni vsepovsod. V Bohinju je bilo v času 1. vojne zelo hudo, saj je bil v neposrednem zaledju soške fronte ... V knjigi je 53 pripovedi, ki v bohinjskih govorih najbolj avtentično izražajo pripovedovalčev osebni odnos do povedanega. Pisateljica tudi tokrat poudarja in izkazuje, da ima narečje »bogatejše mere za človekovega duha in dušo; s svojimi izraznimi možnostmi močneje izraža svoj etnos, vse njegove posebnosti in slikovitosti $\ll$. (Repinc 2015:9)
\end{abstract}

Številni dogodki, osredotočeni na spominjanju lokalnega, so bili podlaga tudi za prireditve, ki so bile bolj široko zasnovane. Eden od takih dogodkov je bila uradna otvoritev spominske pohodniške poti vzdolž bohinjske oskrbovalne poti leta 2014 v okviru znane Poti miru, ki poteka ob soški fronti. Bohinjska pot je bil zasnovana kot tematska pohodniška pot že leta 2007, v sklopu turistične strategije Bohinja, kar dokazuje, da je bila namenjena širšemu občinstvu že od samega začetka. Stoletnica vojne je postala priložnost za preokvirjanje poti kot del širšega projekta Poti miru, kar se je zgodilo v okviru dvodnevne prireditve v letu 2014.

Dvodnevna prireditev, ki je bila osrednji dogodek bohinjskega stoletnega programa leta 2014, je vsebovala več strategij preokvirjanja. Po eni strani je bila pot posvečena Tomažu Budkoviču, lokalnemu zgodovinarju, ki je imel edinstveno vlogo pri ohranjanju bohinjske vojne zgodovine in dediščine. Po drugi pa bi lahko preimenovanje spominske poti kot del Poti miru razumeli kot strategijo vključevanja, katere cilj je bil povezati dogodke zaledja s širšo zgodovino soške fronte. Končno so se organizatorji tudi s preimenovanjem bohinjske poti želeli povezovati $\mathrm{z}$ večjo spominsko potjo, $s$ priznano tržno znamko, ki vabi številne obiskovalce in ji omogoča dostop do zgodovine, ki je zakoreninjena v lokalni pokrajini, vendar je del globalne dediščine (Lotrič Ogrin 2015:3). 
V razpravi o stoletnih dejavnostih po državah v Evropi je jasno, da nacionalne posebnosti vplivajo tako na oblikovanje spominskih programov kot pri opredelitvi njihovega širšega pomena. $V$ luči raznolikosti državnih spominskih programov, tudi med državami, ki so se borile druga proti drugi, postane jasno, da je težko ponuditi ocene o kakršnih koli dokončnih spremembah glede vloge države kot spominskega akterja in o samem pojmu tradicionalne vloge države na splošno. Poleg tega je pomembno upoštevati komemorativne dejavnosti držav na več ravneh, kar vpliva tudi na to, kako državni akterji pojmujejo in se sklicujejo na inkluzivnost, da bi nagovorili in dosegli čim več ciljnih občinstev stoletnih prireditev.

$\mathrm{V}$ primeru transnacionalnih stoletnih prireditev ni opaziti razvoja kakšnega enotnega skupnega okvira ali novega skupnega razumevanja vojne. Namesto enega skupnega razumevanja Evrope prepoznamo več pojmovanj Evrope; vsako ima lahko svoj pomen in namen - odvisno od spominskih akterjev in praks. Poleg tega imajo nacionalni akterji uveljavljeno zgodovino transnacionalnega sodelovanja, kar zadeva komemoracije prve svetovne vojne. Sklicevanje na Evropo je zlasti s strani državnih voditeljev pogosto podrejeno mednarodni politiki na ravni EU.

Lahko zaznavamo decentralizacijo programov ob stoletnici vsaj v primeru Slovenije -, ki se ne nanaša toliko na zmanjšanje aktivnosti na nacionalni ravni, temveč na močno povečanje delovanja na lokalnih in regionalnih ravneh. $\mathrm{V}$ primeru Slovenije ta sprememba ne pomeni nujno praznovanje lokalnih zgodovin $\mathrm{v}$ stoletnih komemoracijah, kot trdi Winter (2017) v primeru Francije. Zdi se, da je imela rast lokalnih in regionalnih dejavnosti vsaj dva rezultata. Po eni strani je stoletnica postala priložnost konkretnega spominjanja o tem, kako je vojna prizadela kraje in regije po vsej Sloveniji, česar državne komemoracije praviloma ne tematizirajo. Po drugi pa je ob stoletnici glede na aktivno vlogo ustanov, lociranih ob Soči, izrazit tudi poudarek na komemoraciji dogodkov ob soški fronti.

Kot kaže, je tudi v Bohinju, ki ima uveljavljeno zgodovino komemorativne prakse, stoletnica postala priložnost za vključitev in poudarjanje lokalnih izkušenj v kraju, kjer so prebivalci raziskovali svojo zgodovino nedavno zapostavljenega obdobja. V teh prireditvah lahko razbiramo številne registre. Tako imajo letne komemoracije 1. novembra na vojaških pokopališčih v Bohinju, ki jih organizirajo lokalne oblasti in institucije, mednarodno razsežnost, saj se jih udeležujejo tuji povabljeni udeleženci, prav tako so vsebine mednarodne. Na podoben 
način je uveljavljena praksa spominskih pohodov, povezanih s soško fronto, ki so jih sprva organizirale številne lokalne pohodniške organizacije iz cele regije. Ob stoletnici so postale pomembnejše turistične organizacije, ki se ne ukvarjajo le s spominom na lokalno zgodovino in izkušnje, temveč tudi s posredovanjem te zgodovine širšemu občinstvu, tudi turistom. To dosegajo s strategijami vključevanja, prizadevanji za vključitev zgodovine lokalnega zaledja in izkušenj v horizont soške fronte v obliki Poti miru, a tudi s širšo zgodbo o prvi svetovni vojni. Na ta način lokalni spominski dogodki kažejo na večkratno preokvirjanje, saj ne pomenijo le komemoracije lokalne vojne zapuščine za lokalno skupnost, ampak prikazujejo in spodbujajo pojmovanje lokalne zgodovine in izkušenj kot del širšega svetovnega zgodovinskega procesa. Pogosto se ta proces ne opredeljuje le kot evropski, temveč predvsem zaradi turistične razsežnosti prireditev nakazuje, kako široko je definiran predvideni naslovnik. Številni dogodki, ki se izvajajo na ravni skupnosti, so namenjeni posredovanju svarilnega sporočila o zgodovinski lekciji vojne vsem in spodbujajo glavno misel njihove aktivnosti, to je pomen miru.

\section{VIRI}

Bajuk SenČar, TAtiana 2018 From the Hinterland: Commemorating the Centenary of World War I in Bohinj; Folklore: Electronic Journal of Folklore, št. 73, str. 47-66.

BAYER, MARTIN 2015 Commemoration in Germany: Rediscovering History; Australian Journal of Political Science, št. 3, str. 553-561.

Beaumont, Joan 2015 The Politics of Memory: Commemorating the Centenary of the First World War; Australian Journal of Political Science, št. 3, str. 529-535.

BBC News 2014 EU leaders Gather for WWI Memorial Ahead of Juncker Battle. 26. 6. 2014. URL: https://www.bbc.com/news/world-europe-28041155

Bell, Duncan 2006 Memory, Trauma and World Politics: Reflections on the relationships Between Past and Present. London: Palgrave Macmillan.

Berliner, DAvid 2005 Social Thought \& Commentary: The Abuses of Memory: Reflections on the Memory Boom in Anthropology; Anthropological 2uarterly, št. 1 , str. 197-211.

Bud Kovič, Toмaž 1999 Bohinj 1914-1918: med fronto in zaledjem. Celovec: Mohorjeva založba.

Chazan, David 2016 Verdun Centenary: Francois Hollande and Angela Merkel Make Impassioned Plea for European Unity. The Telegraph 26. 5. 2016. URL: https://www.telegraph.co.uk/news/2016/05/29/verdun-battle-centenaryfrancois-hollande-and-angela-merkel-to-m/ 
Cvetek, MARIJA 201. Hude so res vojské.... Bohinjske pripovedi o 1. svetovni vojni. Celje: Celjska Mohorjeva družba.

Graves, Matthew 2014 Memorial Diplomacy in Franco-Australian Relations; Shanti Sumartojo in Ben Wellings, ur. Remembering the Great War: memory, nation and commemoration, str. 169-187. Oxford: Peter Lang.

Lotrič Ogrin, Petra 2012 Komemoracija padlim v 1. svetovni vojni; Bohinjske novice, november, str. 7.

2015 Bohinjski del Poti miru iz Posočja. Bohinjske novice, oktober, str. 3.

Jansen-Verbeke, Myriam \& Wanda George 2013 Reflections on the Great War Centenary: From Warscapes to Memoryscapes in 100 Years; Richard Butler in Wantanee Suntikul, ur. Tourism and War, str. 273-287. London \& New York: Routledge.

Jezernik, BožIdar In JuRij Fikfak 2018 Cultural Heritage of the Great War; Traditiones, št. 1, str. 7-32.

Košnik, Katarina 2015100 let začetka soške fronte. MojaObčina.si 16. 4. 2015. URL: https://www.mojaobcina.si/bohinj/novice/obvestila/dogodki/100-let-zacetka-soske-fronte.html (18. 9. 2018).

Kozorog, Mina 2018 Knowledge of Place in Three Popular Music Representations of the First World War; Folklore: Electronic Journal of Folklore, št. 73, str. 67-94.

Kravanja, Boštjan 2018 Learning by Collecting: Amateur Collectors and Their Shifting Positions in the Isonzo Front Heritagization and Tourism Adaptation; Folklore: Electronic Journal of Folklore, št. 73, str. 95-116.

Macdonald, Sharon 2013 Memorylands: Heritage and Identity in Europe Today. London: Routledge.

Mombauer, Annika 2017 The German Centenary of the First World War; War and Society, št. 4, str. 276-288.

News European Parliament 2014 Never Again? Debate to Mark WW1 centenary. 16 4. 2014. URL: http://www.europarl.europa.eu/news/en/headlines/ eu-affairs/20140415STO44548/never-again-debate-to-mark-ww1-centenary

Novica Ministrstvo za obrambo 2014 Poslanstvo nacionalnega odbora za obeleževanje 100-letnic 1. svetovne vojne je utrjevanje kolektivnega zavedanja o posledicah 1. svetovne vojne. 8. 4. 2014. URL: http://www.mo.gov.si/si/ medijsko_sredisce/novica/7085/

Pennell, Catriona 2017 Choreographed by the Angels? Ireland and the Centenary of the First World War; War and Society, št. 4, str. 256-275.

REPIČ, JAKA 2018 Memorialization of the First World War in the Landscape of the Julian Alps; Folklore: Electronic Journal of Folklore, št. 73, str. 27-46.

REPINC, URŠKA 2015 Predstavitev nove knjige Marije Cvetek; Bohinjske novice, april, str. 9.

SAlazAR, Noel B. 2009 Imaged or Imagined? Cultural Representations and the $\gg$ Tourismification « of Peoples and Places; Cahiers d'études africaines, št. 193-194, str. 49-71. 
Wellings, Ben 2016 First World War Commemorations in Belgium and the Netherlands: Comparative Perspectives; BMGN - Low Countries Historical Review, št. 3, str. 99-109.

Winter, Caroline 2009 Tourism, Social Memory and the Great War; Annals of Tourism Research, št. 4, str. 607-626.

Winter, JAY 1995 Sites of Memory, Sites of Mourning: The Great War in European Cultural History. Cambridge: Cambridge University Press.

WINTER, JAY 2017 Commemorating catastrophe: 100 years on; War \& Society, št. str. 4, str. 239-255.

Wouters, Nico 2016 The Centenary Commemorations of the Great War in Belgium; BMGN - Low Countries Historical Review, št. 3, str. 76-86.

\section{Internetni viri:}

http://www.100letprve.si/noga/nacionalni_odbor_za_obelezevanje_100letnic_1_ svetovne_vojne/

http://www.100letprve.si/dogodki/index.html 